This is a self-archived - parallel published version of this article in the publication archive of the University of Vaasa. It might differ from the original.

\title{
Modelling and simulation of hybrid PV \& BES systems as flexible resources in smartgrids - Sundom smart grid case
}

Author(s): Parthasarathy, Chethan; Hafezi, Hossein; Laaksonen, Hannu; Kauhaniemi, Kimmo

Title: $\quad$ Modelling and simulation of hybrid PV \& BES systems as flexible resources in smartgrids - Sundom smart grid case

Year: $\quad 2019$

Version: Accepted manuscript

Copyright (C)2019 IEEE. Personal use of this material is permitted. Permission from IEEE must be obtained for all other uses, in any current or future media, including reprinting/republishing this material for advertising or promotional purposes, creating new collective works, for resale or redistribution to servers or lists, or reuse of any copyrighted component of this work in other works.

\section{Please cite the original version:}

Parthasarathy, C., Hafezi, H., Laaksonen, H., \& Kauhaniemi, K., (2019). Modelling and simulation of hybrid PV \& BES systems as flexible resources in smartgrids - Sundom smart grid case. In: 2019 IEEE Milan PowerTech, Milan, Italy. Institute of Electrical and Electronics Engineers (IEEE). https://doi.org/10.1109/PTC.2019.8810579 


\title{
Modelling and Simulation of Hybrid PV \& BES Systems as Flexible Resources in Smartgrids - Sundom Smart Grid Case
}

\author{
Chethan Parthasarathy, Hossein Hafezi, Hannu Laaksonen, Kimmo Kauhaniemi \\ School of Technology and Innovation, Electrical Engineering \\ University of Vaasa \\ Vaasa, Finland-65200 \\ chethan.parthasarathy@uwasa.fi
}

\begin{abstract}
Ever-growing energy needs and larger penetration of renewable energy in the power grids with higher intermittency in power generation cause the need for flexible energy sources. Flexible sources such as distributed generation, demand response, electric vehicles etc. play a dominant role in providing flexibility in services such as frequency, voltage and power balance control in smart grids. Given the present state of technology and economic maturity of battery energy storage systems (BESS), has a lot of potential to fulfill increasing power systems rapid, short-term flexibility needs. In this paper, a case study on hybrid photovoltaic (PV) arrays \& lithium ion based BESS as flexible energy sources are integrated in medium voltage (MV) network side in local pilot network, Sundom Smart Grid (SSG). Vaasa, Finland. Sundom Smart grid is modelled based on real time data on energy consumption and generation streamed from network. Role of batteries as a flexible energy source in the PV \& BESS hybrid for power balance flexibility application is demonstrated by means of Matlab simulations.
\end{abstract}

Keywords- Microgrid, battery energy storages, lithium ion batteries, Flexible energy sources, DC/DC converter controls, DC/AC VSC controls.

\section{INTRODUCTION}

Explosive growth in energy demand and need for its secure supply has posed varied challenges on primary energy availability. Factors such as aging transmission systems, distribution infrastructure, security, reliability and power quality have been motivating development of innovative grid architectures such as microgrids etc. European Union (ETIPSNET) vision emphasizes on a low-carbon, secure, reliable, resilient, accessible, cost-efficient, and market-based panEuropean integrated energy system, capable of supplying the whole economy and paving the way for a fully $\mathrm{CO}_{2}$-neutral and circular economy by the year 2050, while maintaining and extending global industrial leadership in energy systems during the energy transition [1]. Smartgrids with decentralized and distributed power generation technologies provide an edge in such innovative solutions by limiting transmission \& distribution losses, improved economic dispatch, improved reliability \& power quality and introducing higher degree of flexibility [2].

Strong EU policy framework on cleaner energy has led to rapid increase in the integration of renewable energy systems (RES) such as wind turbine generators (WTG) and PV energy systems in the grids. This enables the need for higher flexibility in distributed power generation considering their intermittency. Intermittent behavior of RES and DGs are due to their dependency on environmental and meteorological conditions, which causes RES energy output to fluctuate for a localized small capacity microgrid (MG) with more than $10 \%$ of the RES occupation [3].

BESS play a critical role in providing flexibility in such smartgrids, by acting as small electric power system being able to operate individually in physically islanded or interconnected mode with the utility grids. BESS, along with being a small electric system also has the potential to participate in multitude of services. Apart from facilitating integration of RES, they also play critical roles in energy arbitrage, optimization of sources in MG, power quality improvement and ancillary services such as load following, operational reserve, frequency regulation etc. [4]. Fig. 1 depicts requirement of ESS for a wide range of application in smartgrids.

Lithium ion batteries (LIB) based BESS are gaining prominence for its role in tapping the potential of renewable energy sources due to higher energy and power density [5], with increased safety of battery chemistries in recent times. They are also capable of providing almost all the services mentioned in Fig. 1. LIBs are modular in structure, where scaling up or down the size of the batteries are relatively easier, thereby expanding their importance in smartgrids.

In this paper, a case study about integration of hybrid PV \& LIB based BES system in MV network of SSG (in Vaasa, Finland) is studied. Modelling SSG with the battery-PV hybrid system and design of needed DC/DC converters and DC/AC voltage source converter controllers are presented in the following sections. 


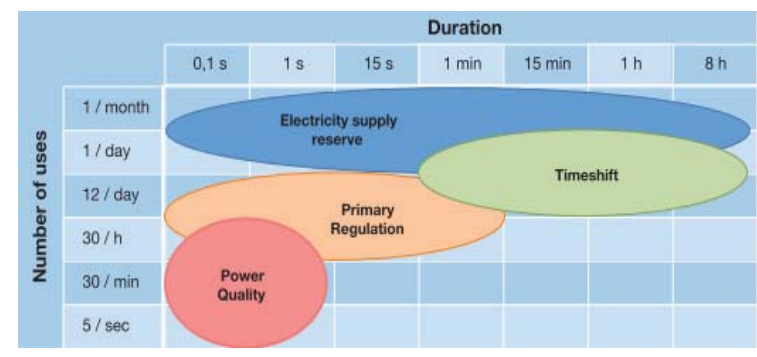

Figure 1. Application of electrical energy storage in microgrids, depending on the frequency and duration of use [6]

\section{SUNDOM SMART GRID}

SSG is a pilot living lab jointly created by $\mathrm{ABB}$, Vaasan Sähköverkko (DSO), Elisa (communications) and University of Vaasa [7]. The overview of the system is presented in Fig. 2. Real-time measurements are recorded from the MV distribution network on-line, from all four feeders at a HV/MV substation as well as from three MV/LV substations comprising 20 measurement points totally. The measured data is IEC 61850 stream with current and voltage measurements. The sampling rate is 80 samples per cycle. In addition power, frequency, RMS voltages, currents etc. measurements are received by GOOSE messages. The data is collected to servers for providing data also for future research.

\section{SSG SYSTEM AND COMPONENT MODELLING}

\section{A. Smartgrid system model}

SSG is modelled as accurately as possible with available data and grid structure in Matlab/Simulink (Simpowersystems). Distribution system is modelled based on data from the local DSO Vaasan Sähköverkko, including all the LV load distribution points and the distribution lines, which lead to them. At each MV load points, i.e. Vaskiluoto, Sundom and Sulva, multiple LV feeder points exist

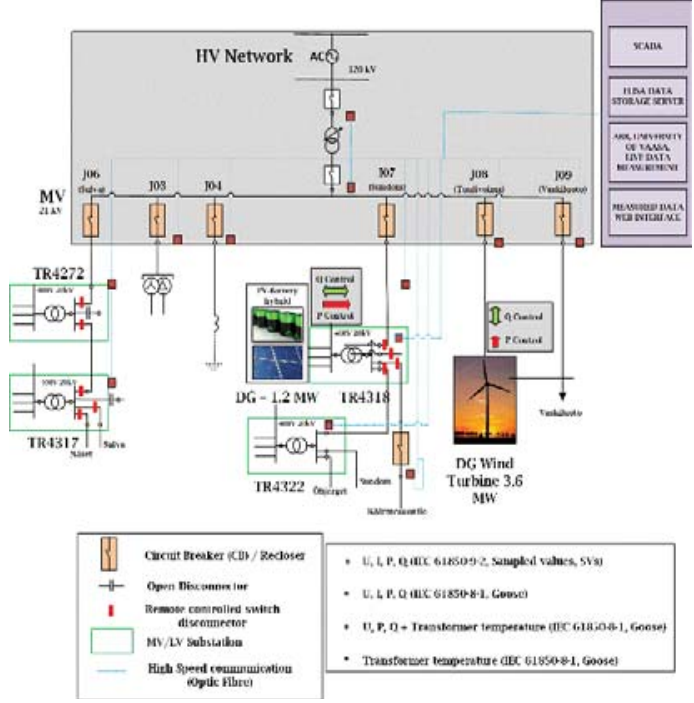

Figure 2. Single line diagram SSG [8]

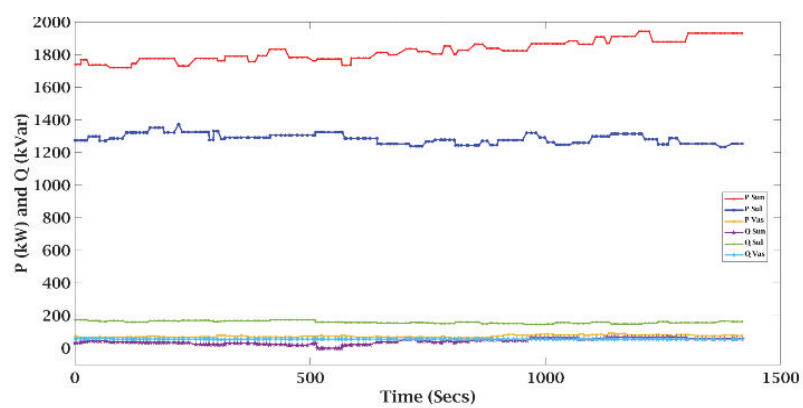

Figure 3. Load Demand at MV buses

Fig. 3 shows the load variations on 30-May-2017 respectively at each MV bus. This period was chosen because the wind power generation was very low (i.e. less than 3.6 MW), which requires implementation of flexible energy resources. Due to the limitation in measurements at distribution side, average load consumption is calculated at each of the MV bus and bus is divided by the number of load centres at each LV distribution points to define load consumption at each LV feeder.

\section{B. Wind Power Modelling}

Wind power generation is modelled from the measured active $(\mathrm{P}$ Wind) and reactive power generation $(\mathrm{Q}$ Wind) at bus Tuulivoima (J08), which is as shown in Fig 4. P_Wind and Q_Wind are then converted to system currents [9], with MV voltage as reference as explained in (1), (2) and (3). Fig. 5 shows injection of Iabc into the MV grid.

$$
\left[\mathrm{S}_{-} \text {Wind }\right]=\left[\begin{array}{l}
P_{\text {Wind }} \\
Q_{\text {Wind }}
\end{array}\right]
$$

$$
\left[\mathrm{V} \_ \text {Grid }\right]=\left[\begin{array}{rr}
V d & V q \\
V q & -V d
\end{array}\right]
$$

$$
\left[\begin{array}{l}
I d \\
I q
\end{array}\right]=\left[\begin{array}{rr}
V d & V q \\
V q & -V d
\end{array}\right]^{-1} *\left[\begin{array}{l}
P_{\text {Wind }} \\
Q_{\text {Wind }}
\end{array}\right]
$$

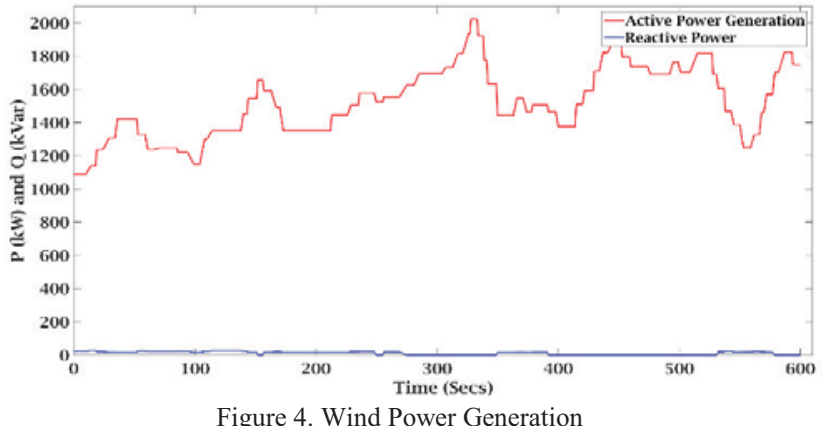




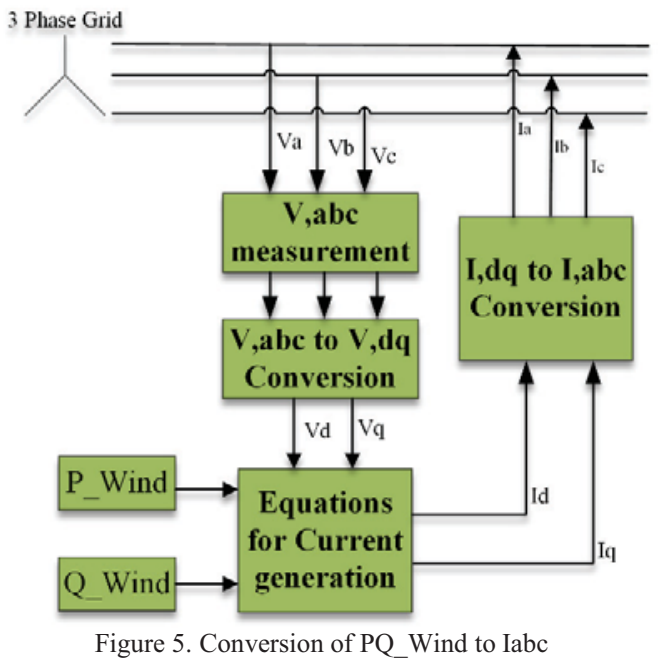

C. Solar $P V \&$ battery hybrid modelling

A $33 \mathrm{~kW}$ solar PV distributed generation is currently existent, which is integrated at Sundom (J07) MV bus. A scale up of existing PV production in parallel with lithium ion battery (LIB) based energy storage system forming a hybrid is proposed, as in Fig. 6 . The hybrid system is sized to provide a peak output of 1.2 MW reliable power output, where LIB based ESSs shall act as flexible energy sources acting as a short time energy source, complimenting the intermittency in PV power. Details of BESS and PV array are mentioned in Table 1 and 2. BESS is modelled on the basis of Shepherd's modelling technique [10]. Discharge characteristics of battery (1C, 2C and $3 \mathrm{C}$ rates) are as shown in Fig 7. Single diode model with losses [11] are used to model solar PV arrays, whose module current-voltage characteristics are defined by (4) and (5). I-V and P-V characteristics of the PV panel are plotted in Fig 8 at $5^{\circ} \mathrm{C}$ and $25^{\circ} \mathrm{C}, 1000 \mathrm{w} / \mathrm{m}^{2}$.

$$
\begin{gathered}
I_{d}=I_{O} *\left[e^{-\left(\frac{V_{d}}{V_{T}}\right)}-1\right] \\
V_{T}=\frac{k T}{q} * n I * N_{\text {Cell }}
\end{gathered}
$$

\footnotetext{
$I_{\boldsymbol{d}} \quad$ Diode current (A)

$\boldsymbol{V}_{\boldsymbol{d}} \quad$ Diode voltage (V)

$\boldsymbol{I}_{\boldsymbol{O}} \quad$ Diode saturation current (A)

nI Diode ideality factor, a number close to 1.0

K Boltzmann constant $\left(1.3806 \mathrm{e}-23 \mathbf{J} . \boldsymbol{K}^{\mathbf{- 1}}\right)$

q electron charge $\left(1.6022 \boldsymbol{e}^{-19} \mathrm{C}\right)$

T cell temperature $(\mathrm{K})$

$\boldsymbol{N}_{\text {Cell }}$ Number of cells connected in series in a module
}

PV array output is boosted by means of boost converter, whose controller is based on perturb and observe ( $\mathrm{P} \& \mathrm{O})$ MPPT algorithm.
Table I. LIB Size and characteristics

\begin{tabular}{|l|l|}
\hline \multicolumn{2}{|c|}{ Lithium Ion Battery Characteristics } \\
\hline Nominal DC voltage & $350 \mathrm{~V}$ \\
\hline Peak Voltage & $407 \mathrm{~V}$ \\
\hline Cut-off Voltage & $262 \mathrm{~V}$ \\
\hline Capacity (0.5 C) & $1110 \mathrm{Ah}$ \\
\hline $\begin{array}{l}\text { Nominal Discharge current }(0.5 \\
\text { C) }\end{array}$ & $482 \mathrm{~A}$ \\
\hline Peak discharge current (3C) & $3330 \mathrm{~A}$ \\
\hline
\end{tabular}

Table II. PV size and characteristics

\begin{tabular}{|l|l|}
\hline \multicolumn{2}{|c|}{ Solar PV Characteristics } \\
\hline Array type & $\begin{array}{l}\text { SunPower SPR-315E- } \\
\text { WHT-D }\end{array}$ \\
\hline Module Voltage at MPP & $54.7 \mathrm{~V}$ \\
\hline $\begin{array}{l}\text { Module Open circuit } \\
\text { Voltage }\end{array}$ & $64.6 \mathrm{~V}$ \\
\hline Module Current at MPP & $5.76 \mathrm{~A}$ \\
\hline Module Max Power & $315 \mathrm{~W}$ \\
\hline Total Series Modules & 5 \\
\hline Parallel strings & 600 \\
\hline
\end{tabular}

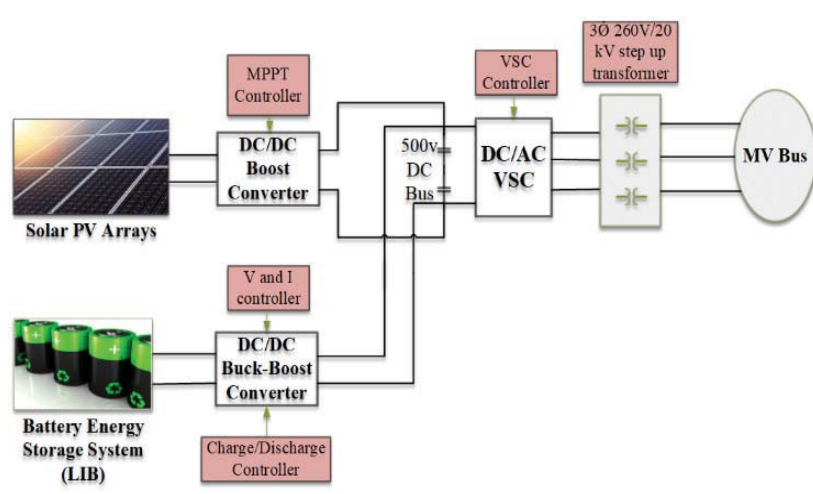

Figure 6. Design of PV and battery hybrid

PV arrays and the lithium ion BESS are integrated in the same DC bus rated at 500V. From Fig. 8, it is evident that PV arrays have a peak power capability of $850 \mathrm{~kW}$ with a maximum current generation of up to $4 \mathrm{kA}$. Remaining energy must be provided by the BESS. DC bus is connected to VSC, which is rated at $1.2 \mathrm{MW}$ and is defined as a function of current from PV arrays (I PV) and BESS (I batt) as in (6). VSC converts $500 \mathrm{Vdc}$ to $3 \varnothing, 260 \mathrm{~V} \mathrm{AC}$, which is then boosted to MV level by means of a transformer.

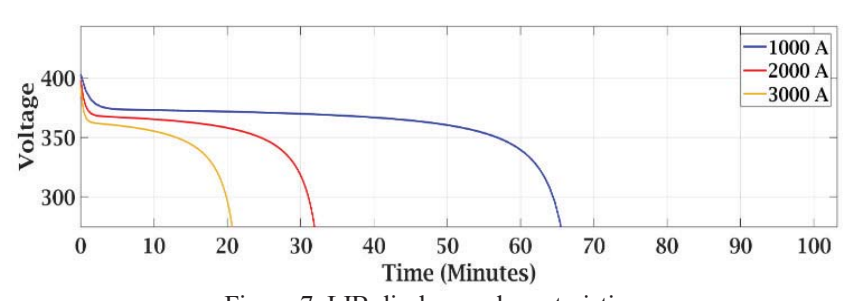

Figure 7. LIB discharge characteristics 

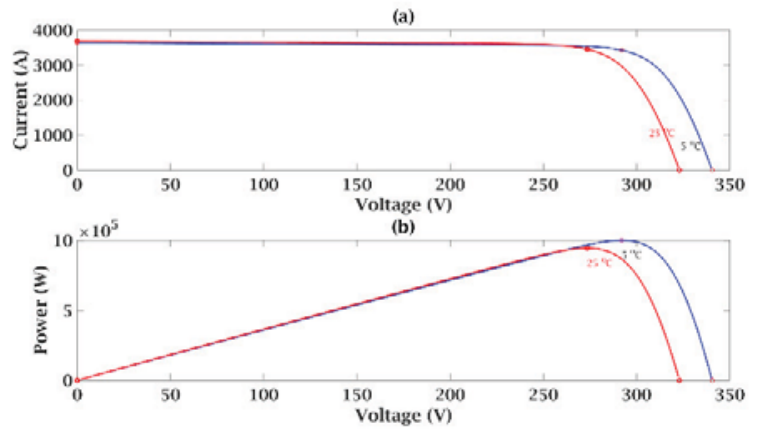

Figure 8. Solar PV array characteristics

$$
P_{I n v}=V_{d c, b u s} *\left(I_{P V}+I_{b a t t}\right)
$$

PV panels have a peak DC output voltage close to $370 \mathrm{~V}$, which is to boosted to $500 \mathrm{~V}$ by means of a boost converter incorporating perturb and observe maximum power point tracking (MPPT) algorithm [12]. In addition, battery stage is connected to the DC bus by means of DC/DC buck-boost converter, where discharging shall be carried out in boost mode and the charging in buck mode. Accurate control for all the power converters are critical considering the nature of application they are serving in this case.

\section{CONTROL OF PV AND BATTERY HYBRID}

Design and operation of the power converter controllers of the PV and battery hybrid are elaborated in this section. They include DC/AC VSC and DC/DC BESS buck-boost controller designs.

\section{A. VSC controller}

Fig 9 describes the VSC controller methodology, which is a voltage oriented control (VOC) technique[13][14]. VOC strategy guarantees fast transient response and high static performance through current control loop. Vabc and Iabc are transformed to V,dq and I,dq frames. Id,ref is obtained by the PI controller for $\mathrm{V}, \mathrm{dc}$ and the Iq,ref reference is provided by the controller designer based on the application demand. Active power output of the inverter is controlled by Id,ref and Iq,ref controls the reactive power output.

A cross coupling exists between d- and q-axes components, which shall affect the dynamic performance of the controller. Therefore, it is very imperative to decouple the two axes for better dynamic performance [15]. Controller in Fig. 9 incorporates the decoupling of $\mathrm{d}$ - and q-axes.

\section{B. Battery Discharge Controller}

Average model of boost converter is designed to discharge the batteries through DC bus capacitor. During discharging, the LIB voltage is boosted to $500 \mathrm{Vdc}$ while maintaining DC bus voltage constant for inverter to supply load. Controller design is based on cascade PI controller with outer voltage control and inner current controller as in Fig 10. The second PI controller output provides the duty cycle to boost converter.

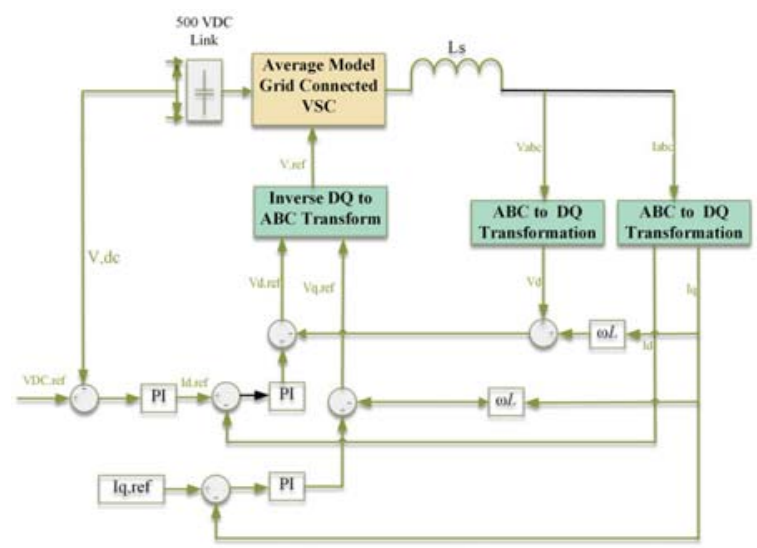

Figure 9. VSC Controller diagram

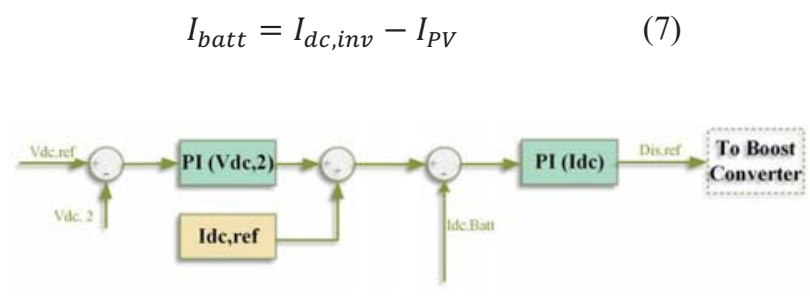

Figure 10. Discharging controller

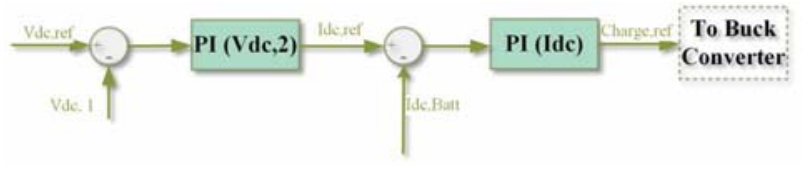

Figure 11. Charge controller

Discharge mode works in the range between $20 \%$ to $90 \%$ of battery SoC, as per the current requirements commanded based on the current required by the inverter. During discharge mode, the inverter current requirement limits the battery current to safe operation limits, which is expressed in (7). Ibatt is the battery current (in Fig 10), Idc, Inv is current requirement at the inverter based on its power rating and IPV is the Solar PV current.

\section{Battery Charge Controller}

Average model of buck converter is designed to charge the batteries using voltage through DC bus capacitor. Constant current (CC) protocol is employed for charging the battery system, as the maximum State of Charge (SoC, Max), is maintained at $90 \%$, which typically is achieved by constant current charging alone, eliminating constant voltage (CV) requirements. Battery charge and discharge mode is based on state of charge $(\mathrm{SoC})$ of the system. Charge controller triggers buck mode of the converter ON when SoC goes below $20 \%$ and turns OFF when it reaches maximum of $90 \%$.

Fig 11 depicts the buck converter controller principle. The difference between nominal voltage value and measured voltage is fed to the PI controller, and the output is considered as the current reference, which is used as reference to the 
(a)

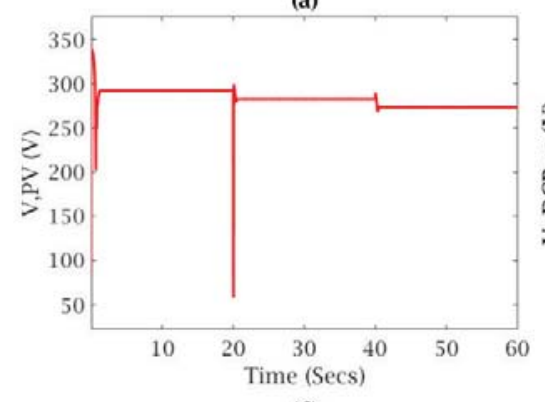

(d)

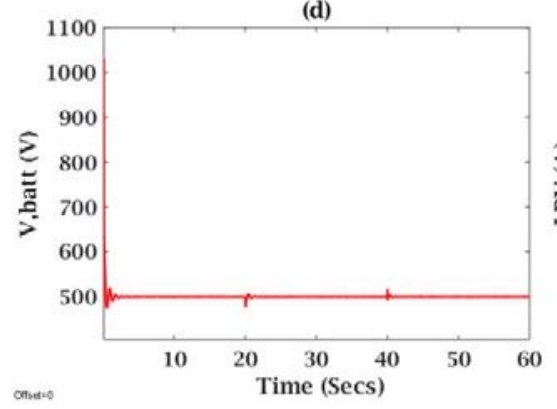

(b)

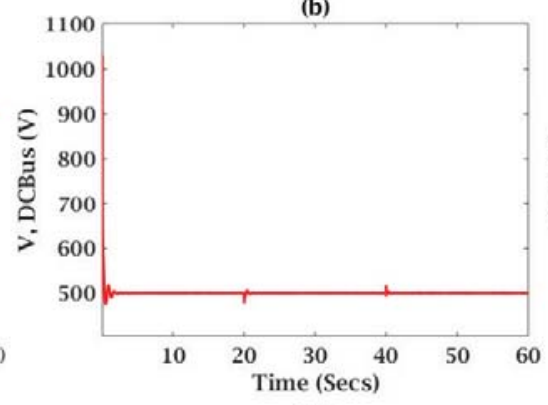

(e)

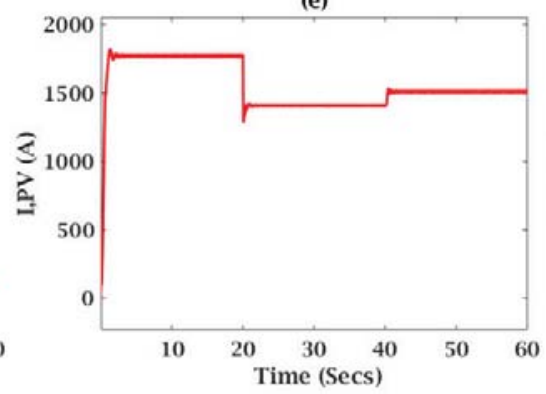

(c)

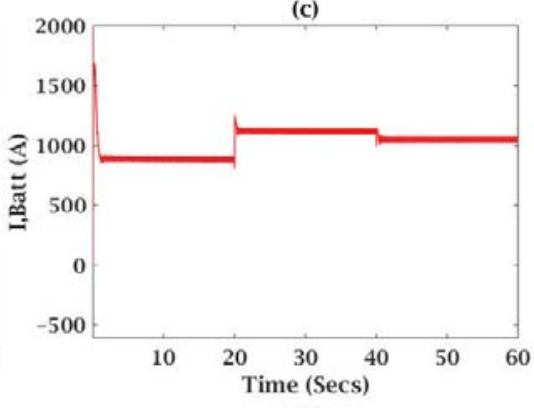

(f)

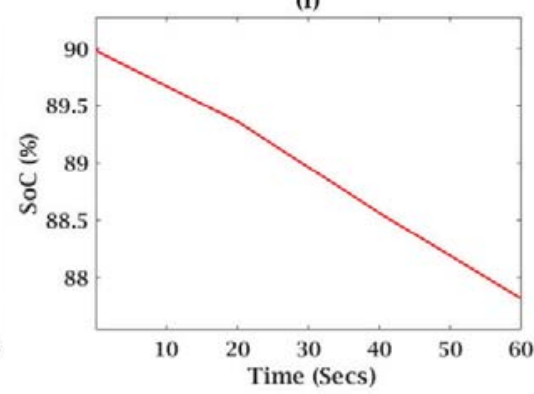

Figure 12. PV array voltage; (b) Controlled voltage at DC bus; (c) Battery current; (d) Controlled battery converter DC voltage ; (e) PV current; (f) Battery SoC;

constant current charge controller. Table 3 presents the regulator gains of PI controllers employed.

\section{Simulation Results AND Discussion}

As explained in section 4, SSG was accurately modelled, both in component and system level by means of the measured characteristics. The case study was performed to validate the role hybrid PV and BESS integration in the MV. The use case study was intended to study the stability of DC/AC converter and battery discharge control by means of $\mathrm{DC} / \mathrm{DC}$ boost converter, validating it in terms of transient \& steady state behavior. It also aids in sizing of BESS for short-term power supply in smart grid applications.

Table III. Controller Coefficients
\begin{tabular}{|c|c|c|}
\hline Controller Coefficients & Kp & Ki \\
\hline VSC DC voltage regulator & 0.5 & 15 \\
\hline VSC Current regulator & 0.3 & 6 \\
\hline Discharge Controller (V,dc) & 0.01 & 2 \\
\hline Discharge Controller (I,dc) & 0.01 & 1 \\
\hline Charge Controller (Idc) & 0.02 & 0.1 \\
\hline
\end{tabular}

Based on the solar irradiance $\left(I_{r}\right)$ and temperature $(T)$ characteristics recorded in [16], three different data sets were chosen within total simulation time $\left(T_{s}\right)$ is $60 \mathrm{secs}$, where intermittency is introduced after every 20 seconds. $I_{r}$ and $T$ for $T_{1}$ were defined based on the recorded average for the month of July 2017. Similarly, $T_{2}$ and $T_{3}$ were the average values in June and May 2017 respectively. These PV variable parameters shall aid in studying the robustness of the hybrid system, when wind power generation in not at its peak. Simulations were performed in discrete mode with time steps of 0.0005 seconds.
Table IV. Simulation details

\begin{tabular}{|c|c|c|}
\hline \multicolumn{3}{|c|}{ Hybrid PV Simulation Case details } \\
\hline $\begin{array}{c}\text { Time Period } \\
\text { (Secs) }\end{array}$ & $\begin{array}{c}\text { Irradiance } \\
\left(\boldsymbol{W} / \boldsymbol{m}^{\mathbf{2}}\right)\end{array}$ & $\begin{array}{c}\text { Temperature } \\
\left({ }^{\circ} \mathbf{C}\right)\end{array}$ \\
\hline T1 (0-20) & 1000 & 5 \\
\hline T2 (20-40) & 900 & 15 \\
\hline T3 (40-60) & 800 & 25 \\
\hline
\end{tabular}

Fig 12 explains the performance of PV and BESS for the entire length of simulation period. PV output voltage (V,PV) reduces at each time steps (i.e. T1 through T3) inducing transients, which is evident from Fig 12(a). Fig 12 (b) displays the DC link voltage (V,DCLink), which is maintained at $500 \mathrm{~V}$ despite the transients induced in the system at time periods T2 and T3, thereby verifying the operability of the hybrid system designed. Fig 12 (c) denotes the battery current (I,batt) discharge characteristics, that are within its safe operating region, which adjusts itself based on the $\mathrm{PV}$ intermittency to supply the set requirements. Fig 12 (d) shows DC voltage at the boost converter, which is controlled at $500 \mathrm{~V}$. Changes in current generated from PV (I,PV) in different time periods is evident in Fig 12(e). Fig 12(f) describes the battery SoC, which reduces almost $2 \%$ during the simulation period, thereby reinstating its role as short-term power supply source capable of complementing the intermittent generation from renewable energy sources.

Power supply into the SSG system from renewable energy resources is presented in Fig 13. Wind power output is based on data recorded from 0 to 60 seconds (Fig. 4). It is noted that a high level of intermittency appears in this time period starting with a minimal power output, which makes it relevant for the 


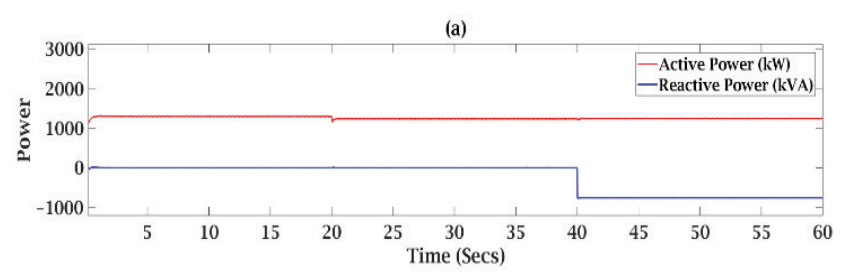

(b)

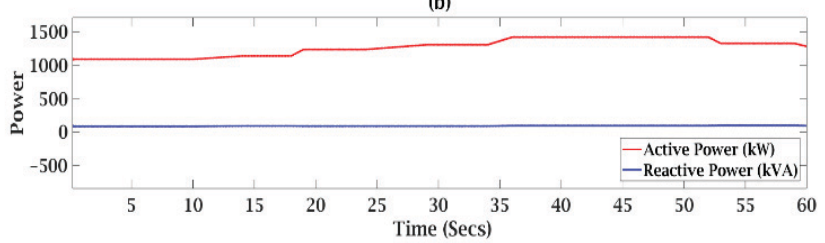

Figure 13. (a) Hybrid PV power characteristics (P \& Q); (b) Wind turbine generator power (P \& Q) characteristics

study conducted, as flexible energy sources shall complement the wind power output downfall. Fig. 13 (b) replicates the active and reactive power characteristics of the WTG, where P fluctuates. Fig 13. (a) represents the P and Q characteristics of the designed hybrid energy source. Active power output is levelled at 1.2 MW, which serves the purpose it was designed of supplying a constant power, where lithium ion BESS solves PV intermittency issue, by acting as a flexible energy source. Inverter is capable of $\mathrm{P} \& \mathrm{Q}$ control respectively, which is demonstrated in period $\mathrm{T} 3$. The inverter absorbs reactive power closer to $400 \mathrm{kVAR}$, thereby enabling improvement of voltage characteristics as and when the MV grid commands.

\section{CONCLUSION}

Flexible energy resources will play a dominant role in the future of power systems, as there is a phase shift in the integration of renewable energy resources globally. Battery energy storages, especially the lithium ion batteries are in the in the forefront of such flexible energy services in the coming decades with their promising characteristics, which spreads across multiple applications.

Accurate design and operation DC/AC power conversion system to facilitate integration of PV and battery hybrid energy source is of paramount importance. Also, LIBs are sensitive in terms of their charge and discharge characteristics, which has to be always maintained in their safe operating area, in order to mitigate thermal runaway conditions. In this paper, a design to carefully discharge and charge LIBs within their threshold is designed and validated by simulation in an existing smartgrid (SSG). Also, the inverter design and control (active and reactive power) are validated for the same application. BESS discharge current characteristics derived from the simulation, i.e. Fig. 12 (c), is the primary indicator for capacity sizing of lithium ion batteries. Accurate sizing of ESS resources are critical due to their operating characteristics and economics [17]. In the study, the scenario considered is one of the most critical cases, due to the limited wind power generation, and the battery sized for this application shall aid in tending almost all the other requirements of flexibility.

In future, role of energy storage system for multiple (i.e. short time and longer time) applications will be studied considering SSG as a case, including its role in steady state and transient stabilities by means of OPAL-RT real time simulator.
Such detailed studies shall aid in accurately designing dispatch strategies for BESS tertiary controller in a hierarchically controlled microgrid systems.

\section{REFERENCES}

[1] T. L. B. N. Hatziargyriou, K. Staschus, "A new focus on innovation / implementation and on sector coupling 2016," 2016.

[2] K. O. Oureilidis and C. S. Demoulias, "An enhanced role for an energy storage system in a microgrid with converter-interfaced sources," J. Eng., vol. 2014, no. 11, pp. 618-625, 2014.

[3] X. Tan, Q. Li, and H. Wang, "Advances and trends of energy storage technology in Microgrid," Int. J. Electr. Power Energy Syst., vol. 44, no. 1, pp. 179-191, 2013.

[4] A. Oudalov, T. Degner, F. van Overbeeke, and J. M. Yarza, "Microgrid: Architectures and Control - Chapter 2," Microgrids Archit. Control, pp. $1-24,2003$.

[5] G. Zubi, R. Dufo-López, M. Carvalho, and G. Pasaoglu, "The lithium-ion battery: State of the art and future perspectives," Renew. Sustain. Energy Rev., vol. 89, no. April, pp. 292-308, 2018.

[6] "www.iec.ch/whitepaper/pdf/iecWP-energystorage-LR-en.pdf." [Online]. Available: https://www.iec.ch/whitepaper/pdf/iecWP-energystorageLR-en.pdf. [Accessed: 07-Dec-2018]."

[7] M. Rita-kasari, "Real-Time Research Lab in the Sundom Smart Grid Pilot," no. 352, pp. 1-4, 2016.

[8] H. Laaksonen, "Future-proof Islanding Detection Schemes in Sundom Smart Grid," Cired 2017, no. June, pp. 12-15, 2017.

[9] B. N. Singh, V. Khadkikar, and A. Chandra, "Generalised single-phase pq theory for active power filtering: simulation and DSP-based experimental investigation," IET Power Electron., vol. 2, no. 1, pp. 6778, Jan. 2009.

[10] J. Meng, G. Luo, M. Ricco, M. Swierczynski, D.-I. Stroe, and R. Teodorescu, "Overview of Lithium-Ion Battery Modeling Methods for State-of-Charge Estimation in Electrical Vehicles," Appl. Sci., vol. 8, no. 5 , p. $659,2018$.

[11] S. Shongwe and M. Hanif, "Comparative Analysis of Different SingleDiode PV Modeling Methods," IEEE J. Photovoltaics, vol. 5, no. 3, pp. 938-946, May 2015.

[12] M. A. G. de Brito, L. Galotto, L. P. Sampaio, G. de A. e Melo, and C. A. Canesin, "Evaluation of the Main MPPT Techniques for Photovoltaic Applications," IEEE Trans. Ind. Electron., vol. 60, no. 3, pp. 1156-1167, Mar. 2013.

[13] G. D’Antona, R. Faranda, H. Hafezi, and M. Bugliesi, "Experiment on Bidirectional Single Phase Converter Applying Model Predictive Current Controller," Energies, vol. 9, no. 4, p. 233, 2016.

[14] T. Zhao, Q. Zong, T. Zhang, and Y. Xu, "Study of photovoltaic threephase grid-connected inverter based on the grid voltage-oriented control," Proc. 2016 IEEE 11th Conf. Ind. Electron. Appl. ICIEA 2016, pp. 2055-2060, 2016.

[15] B. Li, S. Huang, X. Chen, and Y. Xiang, "A simplified DQ-frame current controller for single-phase grid-connected inverters with LCL filters," 2017 20th Int. Conf. Electr. Mach. Syst. ICEMS 2017, 2017.

[16] "JRC's Directorate C, Energy, Transport and Climate - PVGIS - European Commission." [Online]. Available: http://re.jrc.ec.europa.eu/pvgis/. [Accessed: 25-Nov-2018].

[17] C. Parthasarathy, S. Dasgupta, and A. Gupta, "Optimal sizing of energy storage system and their impacts in hybrid microgrid environment," in 2017 IEEE Transportation Electrification Conference (ITEC-India), 2017, pp. 1-6. 